\title{
Sow performance in multi-suckling pens with different management routines
}

\author{
Ola Thomsson 1,2, Ulf Magnusson 1,3, Ann-Sofi Bergqvist 1,3, Lena Eliasson-Selling 1,3,4 \\ and Ylva Cecilia Björnsdotter Sjunnesson ${ }^{1,3^{*}}$
}

\begin{abstract}
Production systems with group housing of sows during a part of the lactation are used in certified organic production and can increase the occurrence of lactational estrus thus making batch-wise breeding difficult. The aim of this study was to investigate the occurrence of lactational estrus and time at return to estrus after weaning by following the performance of the sow (change in body weight, back fat and litter size) in three different management routines. The sows and their litters were moved from individual to multi-suckling pen at one (W1; $n=14$ ), two (W2; $n=13$ ), or 3 weeks $(W 3 ; n=16)$ post farrowing. All sows had a total lactation of 6 weeks. Ovulation was monitored by analysis of fecal progesterone metabolites. Only one sow (W3) ovulated during lactation. Sows in the W2 and W3 groups had a shorter weaning-to-standing estrus interval than W1-sows $(2.6 \pm 0.3 ; 2.7 \pm 0.2$ and $4.0 \pm 0.3$ days respectively, $\mathrm{P}<0.001)$. The $\mathrm{W} 1$-sows and piglets might have kept their nursing bond more intact all through the group housing since the piglets were completely dependent on the nursing at the time of their move to the group pen, thereby staying in lactational anestrus and retaining standard weaning-estrous interval. There was no difference in litter size at grouping or at weaning between management routines and parities. Third and later parity sows had significantly thicker back fat at farrowing and at weaning than 1st and 2nd parity sows $(P<0.05)$. In conclusion, the occurrence of lactational estrus can be low in a multi-suckling pen and the interval between farrowing and move to a multi-suckling pen can affect the weaning to estrus interval. The short weaning-to-standing estrus interval seen in W2 and W3 suggests that estrus detection should start immediately post weaning for sows kept in multi-suckling pens.
\end{abstract}

Keywords: Back fat, Estrus, Group housing, Lactational estrus, Litter size, Pig reproduction, Weaning to estrus interval

\section{Findings}

Production systems with group housing of sows during a part of the lactation are used in some niche production systems such as certified organic production [1]. Keeping lactating sows in multi-suckling pens rather than individual farrowing pens can impair production through increased occurrence of lactational estrus [2, 3]. The return to estrus usually occurs in late lactation, particularly among older sows and sows in good body condition, and this late occurrence results in a prolonged weaningto-service interval, making batch-wise breeding difficult $[2,4,5]$.

\footnotetext{
*Correspondence: ylva.sjunnesson@slu.se

${ }^{1}$ Division of Reproduction, Department of Clinical Sciences, Swedish University of Agricultural Sciences, SLU, P.O. Box 7054, 75007 Uppsala, Sweden

Full list of author information is available at the end of the article
}

The aims of this study were to investigate (1) occurrence of estrus during lactation and weaning-to-estrus interval in three management routines and (2) differences in other aspects of sow performance, i.e. weight, back fat, weight loss, and back fat loss during lactation, and litter size at onset of group housing and at weaning.

The study was performed at Funbo Lövsta, Uppsala. A total of 43 Yorkshire sows were included in the study. The sow and piglets spent either 1 (W1), 2 (W2), or 3 (W3) weeks in an individual farrowing pen (available free space for the sow was $6.4 \mathrm{~m}^{2}$ and straw bedding was provided on top of hard floor surface) before being group housed in a multi-suckling pen. Each management routine was repeated once. Due to the variation in farrowing dates, it took between 1 and 3 days for all sows in each management routine to reach the multi-suckling pen. The time of the move for individual sows was included in 
the statistical information as "subset". Weaning occurred at 6 weeks post farrowing. Descriptions of the sows at farrowing and onset of group housing can be found in Tables 1 and 2.

Table 1 Differences between management routines (W1W3) with regard to litter size, lactation length, weight, and back fat at farrowing and weaning (Lsmeans \pm S.E), and parity (number of sows)

\begin{tabular}{lllll}
\hline & W1 & W2 & W3 & P \\
\hline Litter size & & & & \\
Live born & $12.5 \pm 0.7$ & $13.3 \pm 0.8$ & $11.8 \pm 0.7$ & n.s. \\
At grouping & $10.4 \pm 0.6$ & $10.4 \pm 0.7$ & $9.8 \pm 0.6$ & n.s. \\
At weaning & $9.0 \pm 0.6$ & $9.6 \pm 0.6$ & $9.6 \pm 0.5$ & n.s. \\
Lactation period & $44.2 \pm 0.6$ & $43.6 \pm 0.6$ & $43.7 \pm 0.6$ & n.s. \\
$\quad$ (days) & & & & \\
Sow weight (kg) & & & & \\
At farrowing & $257.7 \pm 7.8$ & $266.7 \pm 8.2$ & $256.1 \pm 7.6$ & n.s. \\
At weaning & $246.8 \pm 7.3^{\text {ab }}$ & $263.6 \pm 7.6^{\text {a }}$ & $233.5 \pm 7.1^{\mathrm{b}}$ & $<0.05$ \\
Difference & $-11.2 \pm 5.7^{\mathrm{ab}}$ & $-1.0 \pm 6.1^{\mathrm{a}}$ & $-22.4 \pm 5.5^{\mathrm{b}}$ & $<0.05$ \\
Back fat (mm) & & & & \\
At farrowing & $17.5 \pm 1.2$ & $17.4 \pm 1.3$ & $19.0 \pm 1.2$ & n.s. \\
At weaning & $14.0 \pm 1.0$ & $16.8 \pm 1.1^{\mathrm{n}}$ & $15.2 \pm 1.0$ & n.s. \\
Difference & $-3.6 \pm 0.8^{\mathrm{a}}$ & $-0.5 \pm 0.9^{\mathrm{b}}$ & $-3.8 \pm 0.8^{\mathrm{a}}$ & $<0.05$ \\
1st parity & 3 & 2 & 6 & n.s. \\
2nd parity & 6 & 4 & 4 & n.s. \\
> 2nd parity & 5 & 7 & 6 & n.s. \\
\hline
\end{tabular}

Different superscripts within rows indicate significant differences n.s. non-significant $(P>0.5)$

$\mathrm{W} 1=$ The sows and their litters were moved from individual to multi-suckling pen at 1 week post farrowing, W2 $=$ The sows and their litters were moved from individual to multi-suckling pen at 2 weeks post farrowing, $\mathrm{W} 3=$ The sows and their litters were moved from individual to multi-suckling pen at 3 weeks post farrowing
Three multi-suckling pens were constructed in an uninsulated barn as described previously [6]. In brief, space allowance per sow in the multi-suckling pen was according to standards for Swedish organic breeding [1] and ranged from 7.8 to $12.5 \mathrm{~m}^{2}$ depending on the number of sows per pen (5-8 sows/pen). The design is illustrated in Fig. 1. The bedding consisted of straw in the lying area and peat in the feeding area. During the entire lactation period, the sows were fed ad libitum with dry feed in a feeding trough that was accessible to the piglets as well. In addition, sows and piglets had access to hay at all times. Water was provided ad libitum.

During the group housing period daily manual estrus detection tests were performed by inspection vulva swelling and reddening and by applying back pressure. Post weaning, manual estrus detection was performed twice a day with a boar present until estrus was detected.

Fecal samples were collected from the rectum every third day from day 21 post farrowing until the day of weaning and stored at $-20^{\circ} \mathrm{C}$ until analysis.

Sows were slaughtered after the first reported standing estrus post weaning and the reproductive tract was retrieved and examined macroscopically.

At farrowing and weaning, each sow's back fat thickness was measured ultrasonically by experienced staff using a Krautkramer USM22 device (GE Inspection Technology GmBH, Hürth, Germany) at the last rib, between 7 and $8 \mathrm{~cm}$ from the middle of the back [7].

Most of the progesterone in feces is present in a metabolized form [8] and progesterone and its metabolites are referred to hereafter as progestin. The method used for extracting progestin from feces was modified from Palme et al. [9] and Wasser et al. [10]. One gram feces

Table 2 Differences between parities with regard to litter size, lactation length, weight, and back fat at farrowing and weaning (Lsmeans \pm S.E)

\begin{tabular}{|c|c|c|c|c|}
\hline & 1st party sows & 2nd parity sows & $>$ 2nd parity sows & $\mathbf{P}$ \\
\hline \multicolumn{5}{|l|}{ Litter size } \\
\hline Live born & $12.4 \pm 0.9$ & $12.6 \pm 0.7$ & $12.6 \pm 0.7$ & n.s. \\
\hline At grouping & $10.5 \pm 0.7$ & $10.1 \pm 0.6$ & $10.0 \pm 0.6$ & n.s. \\
\hline At weaning & $9.3 \pm 0.7$ & $10.0 \pm 0.6$ & $9.0 \pm 0.5$ & n.s. \\
\hline Lactation period (days) & $43.5 \pm 0.4$ & $43.9 \pm 0.4$ & $44.1 \pm 0.4$ & n.s. \\
\hline \multicolumn{5}{|l|}{ Sow weight (kg) } \\
\hline At farrowing & $213.3 \pm 7.2^{\mathrm{a}}$ & $264.4 \pm 6.1^{b}$ & $302.9 \pm 6.3^{c}$ & $<0.001$ \\
\hline At weaning & $210.9 \pm 8.1^{\mathrm{a}}$ & $244.3 \pm 6.5^{b}$ & $288.7 \pm 6.5^{c}$ & $<0.001$ \\
\hline Difference & $-0.2 \pm 6.3^{\mathrm{a}}$ & $-20.1 \pm 5.0^{b}$ & $-14.4 \pm 5.1^{\mathrm{ab}}$ & $<0.05$ \\
\hline \multicolumn{5}{|l|}{ Back fat (mm) } \\
\hline At farrowing & $16.1 \pm 1.1^{\mathrm{a}}$ & $18.0 \pm 1.0^{\mathrm{a}}$ & $20.3 \pm 1.0^{b}$ & $<0.05$ \\
\hline At weaning & $12.6 \pm 1.3^{\mathrm{a}}$ & $14.8 \pm 1.0^{\mathrm{a}}$ & $18.5 \pm 1.0^{b}$ & $<0.05$ \\
\hline Difference & $-3.0 \pm 1.0$ & $-3.0 \pm 0.8$ & $-1.8 \pm 0.8$ & n.s. \\
\hline
\end{tabular}

Different superscripts within rows indicate significant differences

n.s. non-significant $(P>0.05)$ 


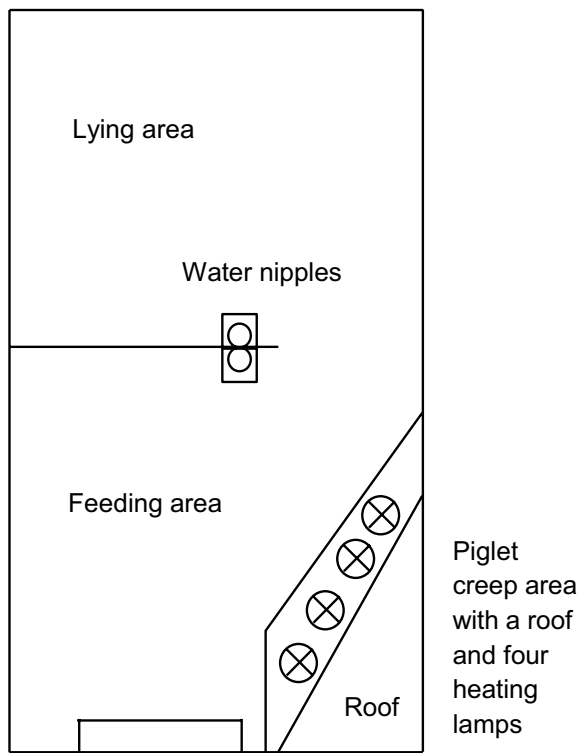

Feeding trough

Fig. 1 Illustration of the multi-suckling pen (reproduced with the permission of BioMed Central original publisher)

was mixed with $10 \mathrm{~mL}$ methanol ( $\geq 99.9 \%)$ and the slurry obtained was shaken for $1 \mathrm{~h}$, followed by $15 \mathrm{~min}$ of centrifugation at $3000 \times g$ at room temperature. Three milliliters of the supernatant was then stored at $-20^{\circ} \mathrm{C}$ until analysis. The analysis was conducted using a solid-phase 125I-radioimmunassay (Coat-a-count Progesterone, Siemens Healthcare Diagnostic Inc, Los Angeles, CA, USA) previously validated for pig feces [7]. The analysis was performed according to the manufacturer's instructions. The inter-assay coefficient of variation for high, medium, and low concentrations was 12, 12 and 14\%, respectively. The intra-assay coefficient of variation was below $10 \%$, within the working range of $0.3-127 \mathrm{nmol} / \mathrm{L}$.

All statistical analyses were performed using SAS software ver. 9.3 (SAS Inst., Cary, NC, USA). To analyze differences between management routines regarding days from weaning to standing estrus, the procedure Mixed was used. Fixed effects included were management routine, repeat, parity, and subset. Litter size at group housing was added as covariate. Random effect was repeat nested within management routine and subset. Subset did not influence the outcomes. To analyze progestin profiles, the 99th and 97.5th \% were calculated from the progestin concentration in every fecal sample [7] collected at day 21 post farrowing. The progestin concentration in the fecal samples collected at day 21 post farrowing was considered to represent anestral levels of progesterone. The 99th \%o was $67 \mathrm{nmol} / \mathrm{L}$ and the 97.5th \%o was $48 \mathrm{nmol} / \mathrm{L}$. Ovulation was considered to

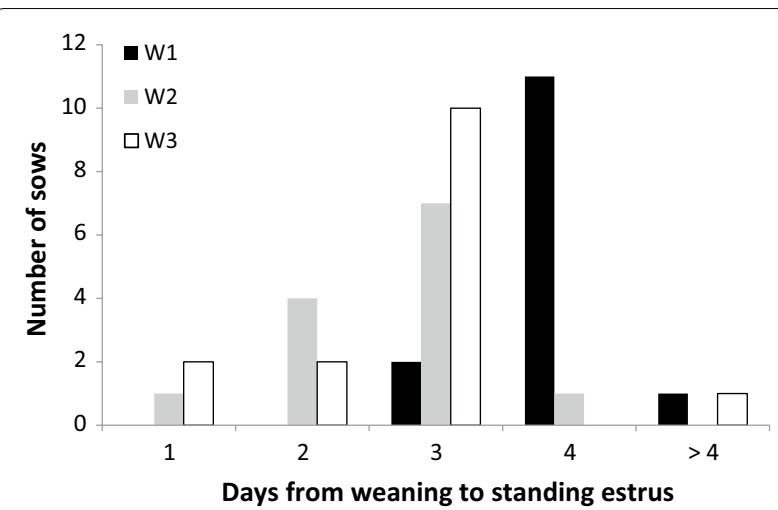

Fig. 2 Days from weaning to standing estrus distribution in different management routines (W1-W3). The interval from weaning to standing estrus was shorter for W2 ( 2.7 days $\pm 0.2 ; P<0.05)$ and W3 ( 2.4 days $\pm 0.2 ; \mathrm{P}<0.001$ ) than $\mathrm{W} 1$ (3.8 days \pm 0.2 ). There was no difference between $\mathrm{W}_{2}$ and $\mathrm{W} 3$

be possible if one fecal sample had a concentration above $67 \mathrm{nmol} / \mathrm{L}$ or if two consecutive fecal samples had a concentration above $48 \mathrm{nmol} / \mathrm{L} . \mathrm{P}<0.05$ were considered significant.

Number of days from weaning to standing estrus differed between the three management routines as illustrated in Fig. 2. The weaning-to-standing estrus interval of sows in management routine W2 (2.6 days \pm 0.3 ; $\mathrm{P}<0.001)$ and $\mathrm{W} 3$ (2.7 days $\pm 0.2 ; \mathrm{P}<0.001)$ was shorter than that of W1-sows (4.0 days \pm 0.3 ; $\mathrm{P}<0.001)$. The majority of weaned sows usually display standing estrus on days four and five post weaning [11-14]. The shorter weaning-to-standing estrus interval for management routines W2 and W3 could therefore be of practical importance. A short weaning-to-standing estrus interval indicates that estrus detection needs to start immediately post weaning since failure to detect the start of standing estrus or the entire standing estrus display can have a negative effect on overall pig production economics. The W1 sows and piglets might have kept their nursing bond more intact all through the group housing since the piglets were completely dependent on the suckling at the time of their move to the group pen, thereby maintaining the lactational anestrus and retaining standard weaningestrous interval.

Mean fecal progestin concentrations for all sows and for two individual sows, one in management routine W1 and one in the W3 routine, that had two samples or more that exceeded the lower threshold level are presented in Fig. 3. Only the W3-sow had a confirmed ovulation (corpora lutea from lactation visible in ovaries at slaughter) during lactation and no explanation was found for the increased progestin concentrations in the W1-sow. The ovulating sow was a 1st parity sow with 12 piglets at birth 


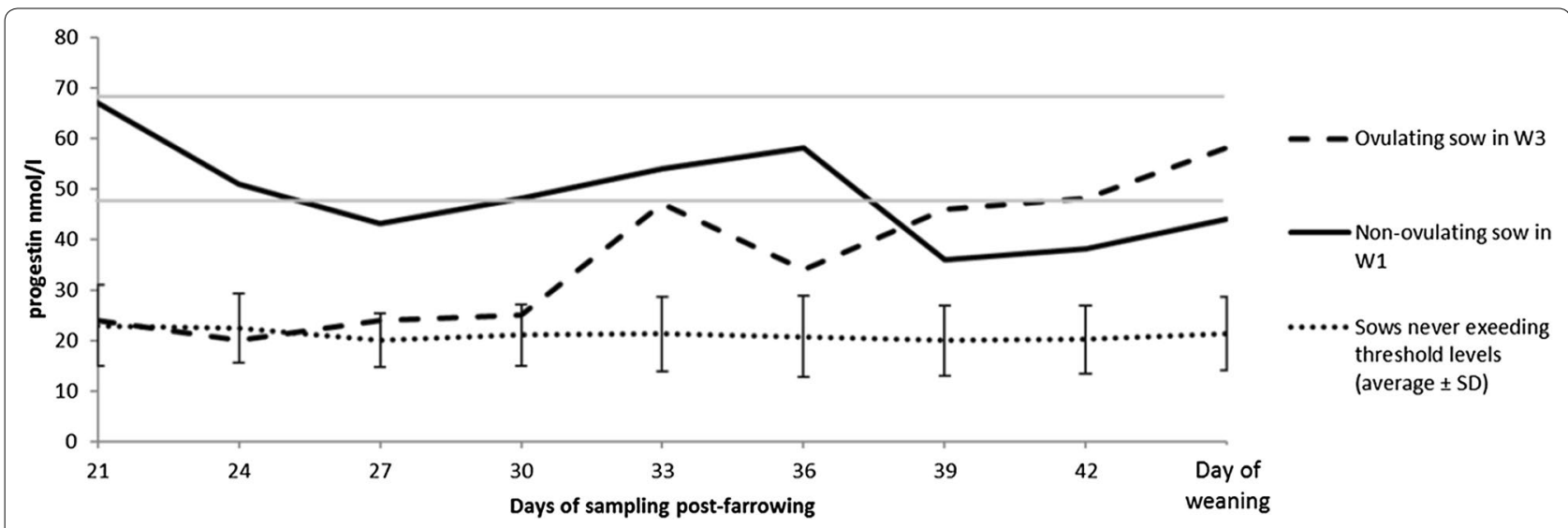

Fig. 3 Fecal progestin concentration profile. Samples from every third day with start on day 21 post-farrowing until the day of weaning for management routines W1, W2 and W3. Threshold levels are visualized (99th \%o with $67 \mathrm{nmol} / \mathrm{L}$ and 97.5 th with $48 \mathrm{nmol} / \mathrm{L}$ ). Mean values of all sows that did not exceed threshold levels as well as values for two sows that had two samples or more that exceeded the lower threshold level are shown

and eight piglets at weaning. The ovulating sow gained $14 \mathrm{~kg}$ and lost $1.5 \mathrm{~mm}$ back fat during lactation, resulting in a back fat depth of $18 \mathrm{~mm}$ at weaning. The weight gain, the back fat depth at weaning, and low back fat loss during lactation for the ovulating sow indicate that the sow had the potential to ovulate during lactation [2]. Since the sows were slaughtered as soon as possible after onset of standing oestrus after weaning, not all sows had ovulated when the reproductive tracts were examined. The mean number of ovulations/sow were 28, 25 and 31 and the mean uterus weight was 851,785 and $851 \mathrm{~g}$ in W1, W2 and W3 respectively. None of the sows in any management routine displayed standing estrus during the lactation period. There is great variation in occurrence of lactational estrus among studies reported in the literature, ranging from $0 \%[15]$ to $100 \%$ when a boar is present $[16,17]$. Another factor known to increase the occurrence of lactational estrus is a pen that allows many social interactions among sows and has many compartments, which reduces the interaction between the sow and her piglets [18]. Pen design might therefore have caused the sows to remain in lactational anestrus during the lactation period in the multi-suckling pen. Hultén et al. [3] investigated sows housed under organic conditions and found the lowest occurrence of lactational estrus during the fall which coincides with when this study was conducted. This might have contributed to the lack of lactational estrus seen in the present study. Regardless of the reason, this study suggests that lactational estrus does not have to be a major problem when sows are kept in multi-suckling pens.

There were no differences between management routines or between parities in the number of live born piglets and litter size at grouping and at weaning (Tables 1 and 2). Body condition loss during lactation also seemed influenced by timing of grouping (with the W2-sows having less body weight and back fat loss) but could be due to individual variation and that the W2 group had numerically less first parity sows than the W1 and W3 group (Table 1). The $>$ 2nd parity sows were heavier and had more back fat than 1st and 2nd parity sows at farrowing and weaning (Table 2). This difference is not surprising, as young sows are still growing and have not accumulated as much back fat as older sows [19, 20]. There was no apparent connection between back fat loss or body weight loss and weaning-to-standing estrus interval. Previous studies have also reported a lack of significant correlation between back fat loss and weaning-to-standing estrus interval [19, 21].

In conclusion, sows group housed at 2 or 3 weeks post farrowing in multi-suckling pens had a shorter interval from weaning to standing estrus than sows group housed at 1 week post farrowing, which had a normal interval. This could be due to differences in nursing-suckling establishment and interaction in the group housing pen. These results suggest that estrus detection should start immediately post weaning for sows kept in multi-suckling pens, in order to avoid missing the onset of estrus. The occurrence of lactational estrus was found to be low in these multi-suckling pens.

\section{Authors' contributions}

OT, ASB, YCBS, UM and LES participated in the planning of the project. OT, $A S B$ and YCBS performed the collection of feces and reproductive tract examination. OT and YCBS were responsible for drafting the manuscript. ASB UM and LES revised the manuscript. All authors read and approved the final manuscript.

\footnotetext{
Author details

${ }^{1}$ Division of Reproduction, Department of Clinical Sciences, Swedish University of Agricultural Sciences, SLU, P.O. Box 7054, 75007 Uppsala, Sweden.
} 
${ }^{2}$ Present Address: The Swedish Research Council for Environment, Agricultural Sciences and Spatial Planning, P.O. Box 1206, 11182 Stockholm, Sweden.

${ }^{3}$ Centre for Reproductive Biology in Uppsala, CRU, P.O. Box 7054, 75007 Uppsala, Sweden. ${ }^{4}$ Farm \& Animal Health, Kungsängens Gård, 75323 Uppsala, Sweden

\section{Acknowledgements}

We want to thank the staff at Lövsta Research Station, Swedish University of Agricultural Sciences. Figure no. 1 was first published in "Aggression and cortisol levels in three different group housing routines for lactating sows" [6].

\section{Competing interests}

The authors declare that they have no competing interests.

\section{Availability of data and materials}

The datasets created during and/or analysed during the current study are available from the corresponding author on reasonable request.

\section{Consent for publication}

Not applicable.

\section{Ethics approval and consent to participate}

The study was approved by the Uppsala Animal Ethics Committee (C154/11). No human data or tissue were used in this study and consent to participate is therefore not applicable.

\section{Funding}

This study was financially supported by the Swedish Research Council Formas. The funding body had no role in the design of the study, collection, analysis, or interpretation of data or in writing of the manuscript.

\section{Publisher's Note}

Springer Nature remains neutral with regard to jurisdictional claims in published maps and institutional affiliations.

Received: 2 October 2017 Accepted: 5 February 2018

Published online: 08 February 2018

\section{References}

1. KRAV: KRAV's standards. 2017. http://www.krav.se/krav-standards. Accessed 30 Aug 2017.

2. Wallenbeck A, Gustafson G, Rydhmer L. Sow performance and materna behaviour in organic and conventional herds. Acta Agric Scand A Anim Sci. 2009:59:181-91.

3. Hulten F, Wallenbeck A, Rydhmer L. Ovarian activity and oestrous signs among group-housed, lactating sows: influence of behaviour, environment and production. Reprod Domest Anim. 2006;41:448-54.

4. Soede N, Laurenssen B, Abrahamse-Berkeveld M, Gerritsen R, Dirx-Kuijken $\mathrm{N}$, Langendijk $\mathrm{P}$, et al. Timing of lactational oestrus in intermittent suckling regimes: consequences for sow fertility. Anim Reprod Sci. 2012;130:74-81.

5. Terry R, Kind KL, Lines DS, Kennett TE, Hughes PE, van Wettere WH. Lactation estrus induction in multi- and primiparous sows in an Australian commercial pork production system. J Anim Sci. 2014;92:2265-74.
6. Thomsson O, Bergqvist AS, Sjunnesson Y, Eliasson-Selling L, Lundeheim $\mathrm{N}$, Magnusson U. Aggression and cortisol levels in three different group housing routines for lactating sows. Acta Vet Scand. 2015;57:9.

7. Hultén F, Dalin AM, Lundeheim N, Einarsson S. Ovulation frequency among sows group-housed during late lactation. Anim Reprod Sci. 1995;39:223-33.

8. Schwarzenberger F, Möstl E, Palme R, Bamberg E. Faecal steroid analysis for non-invasive monitoring of reproductive status in farm, wild and zoo animals. Anim Reprod Sci. 1996;42:515-26.

9. Palme R, Möstl E, Brem G, Schellander K, Bamberg E. Faecal metabolites of infused 14C-progesterone in domestic livestock. Reprod Domest Anim. 1997;32:199-206

10. Wasser SK, Hunt KE, Brown JL, Cooper K, Crockett CM, Bechert U, et al. A generalized fecal glucocorticoid assay for use in a diverse array of nondomestic mammalian and avian species. Gen Comp Endocrinol. 2000:120:260-75.

11. Kemp B, Soede NM. Relationship of weaning-to-estrus interval to timing of ovulation and fertilization in sows. J Anim Sci. 1996:74:944-9.

12. Weitze KF, Wagner-Rietschel H, Waberski D, Richter L, Krieter J. The onset of heat after weaning, heat duration, and ovulation as major factors in Al timing in sows. Reprod Domest Anim. 1994;29:433-43.

13. Tummaruk P, Lundeheim N, Einarsson S, Dalin AM. Reproductive performance of purebred Swedish Landrace and Swedish Yorkshire sows: II. Effect of mating type, weaning-to-first-service interval and lactation length. Acta Agric Scand A Anim Sci. 2000;50:217-24.

14. Sterning $M$, Rydhmer L, Eliasson L, Einarsson S, Anderson K. A study on primiparous sows of the ability to show standing oestrus and to ovulate after weaning. Influences of loss of body weight and backfat during lactation and of litter size, litter weight gain and season. Acta Vet Scand. 1990;31:227-36.

15. Weary DM, Pajor EA, Bonenfant M, Fraser D, Kramer DL. Alternative housing for sows and litters: part 4. Effects of sow-controlled housing combined with a communal piglet area on pre- and post-weaning behaviour and performance. Appl Anim Behav Sci. 2002;76:279-90.

16. Bryant MJ, Rowlinson P, Van der Steen HAM. A comparison of the nursing and suckling behaviour of group- and individually-housed sows and their litters. Anim Sci. 1983;36:445-51.

17. Kongsted $A G$, Hermansen JE. Induction of lactational estrus in organic piglet production. Theriogenology. 2009;72:1188-94

18. Stolba A, Henderson R, Wechsler B. The influence of different social and physical environments on the incidence of lactational oestrus in sows. Appl Anim Behav Sci. 1990;27:269-76.

19. Guedes RMC, Nogueira RHG. The influence of parity order and body condition and serum hormones on weaning-to-estrus interval of sows. Anim Reprod Sci. 2001;67:91-9.

20. Čechova M, Tvardoň Z. Relationships between backfat thickness and parameters of reproduction in the Czech Large White sows. Arch Anim Breed. 2006;49:363-9.

21. Maes DGD, Janssens GPJ, Delputte P, Lammertyn A, de Kruif A. Back fat measurements in sows from three commercial pig herds: relationship with reproductive efficiency and correlation with visual body condition scores. Livest Prod Sci. 2004;91:57-67.

\section{Submit your next manuscript to BioMed Central and we will help you at every step:}

- We accept pre-submission inquiries

- Our selector tool helps you to find the most relevant journal

- We provide round the clock customer support

- Convenient online submission

- Thorough peer review

- Inclusion in PubMed and all major indexing services

- Maximum visibility for your research

Submit your manuscript at www.biomedcentral com/submit
Ciomed Central 